This item was submitted to Loughborough's Research Repository by the author.

Items in Figshare are protected by copyright, with all rights reserved, unless otherwise indicated.

\title{
Ergonomics systems mapping for professional responder inter-operability in chemical, biological, radiological and nuclear events
}

PLEASE CITE THE PUBLISHED VERSION

https://doi.org/10.1007/978-3-319-96098-2_13

\section{PUBLISHER}

Springer

VERSION

AM (Accepted Manuscript)

\section{PUBLISHER STATEMENT}

This is a pre-copyedited version of a contribution published in Bagnara, S. ... et al. (eds.) 20th International Ergonomics Association (IEA2018): Volume I: Healthcare Ergonomics published by Springer. The definitive authenticated version is available online via https://doi.org/10.1007/978-3-319-96098-2_84

\section{LICENCE}

CC BY-NC-ND 4.0

\section{REPOSITORY RECORD}

Hancox, Graham, Sue Hignett, Hilary Pillin, Spyros Kintzios, Jyri Silmari, and C.L. Paul Thomas. 2019. "Ergonomics Systems Mapping for Professional Responder Inter-operability in Chemical, Biological, Radiological and Nuclear Events". figshare. https://hdl.handle.net/2134/34619. 
Hancox, G., Hignett, S., Kintzios, S., Pillin, H., Silmäri, J., Thomas, P. (2018) Ergonomics systems mapping for professional responder inter-operability in Chemical, Biological, Radiological and Nuclear events. . Proceedings of the $20^{\text {th }}$ Triennial Conference of the International Ergonomics Association. Florence, Italy, 26-30 August

\title{
Ergonomics Systems mapping for professional responder inter-operability in Chemical, Biological, Radiological and Nuclear events
}

\author{
Graham Hancox $^{1[0000-0001-7301-6001]}$, Sue Hignett ${ }^{10000-0002-3025-7451]}$, Hilary Pillin ${ }^{2}$, \\ Spyros Kintzios ${ }^{3}$,Jyri Silmäri ${ }^{4}$ and C.L. Paul Thomas ${ }^{[0000-0003-4631-6417] 5}$ \\ ${ }^{1}$ Design School, Loughborough University, Loughborough, UK \\ ${ }^{2}$ HRP Professional Services Ltd, Witney, UK \\ ${ }^{3}$ R\&D Project Management Department, Hellenic Navy, Athens, Greece \\ ${ }^{4}$ Rescue Services, South-Savo Regional Fire Services, Mikkeli, Finland \\ ${ }^{5}$ Centre for Analytical Science, Department of Chemistry, Loughborough University, UK
}

\begin{abstract}
A European consensus was developed as a concept of operations (CONOPS) for cross-border, multi-professional chemical, biological, radiological and nuclear (CBRN) responses. AcciMaps were co-designed with professional responders from military, fire, ambulance, and police services in UK, Finland and Greece. Data were collected using document analysis from both open and restricted sources to extract task and operator information, and through interviews with senior staff representatives (Gold or Silver Command level). The data were represented on the Accimaps as a high level Socio-Technical Systems (STS) map of CBRN response using the themes of communication, planning, action, and reflection. Despite differences between service sectors and in terminology, a macro systems level consensus was achieved for the command structures (Gold, Silver and Bronze), and Hot Zone responders (Specialist Blue Light Responders and Blue Light Responders). The detailed tasks and technologies have been analysed using Hierarchical Task Analysis (HTA) to represent both complex response scenarios (macro) and detailed technologies (micro interfaces) for detection, diagnosis and decontamination. The outputs from these two systems mapping tools (Accimaps and HTAs) are being used in two field trials/exercises.
\end{abstract}

Keywords: Ergonomics, CBRN, NATO, AcciMap, Sociotechnical systems.

\section{Introduction}

Chemical, Biological, Radiological and Nuclear (CBRN) and terrorist events will lead to emergency services having to respond in environments which are dangerous, complex, fast paced, high-stakes, unpredictable and substantially novel [1,2]. CBRN incidents in particular can cause a great deal of psychological stress due to the level of uncertainty both before and after an event has occurred, resulting not knowing where and when they might take place, and when responding through difficulties in identifying the substances involved and how best to deal with them [3]. This can be 
especially true for emergency service responders (Fire, Police and Ambulance) whose actions and decisions within an event can directly save lives [4]. Yet, a lack of knowledge, skills or awareness in CBRN incidents may lead to such professionals being reticent to engage in their duties in the event of such an incident [5].

The scale of mass casualty incidents (MCIs) such as CBRN events often require the cooperation of many varied organisations both on the ground and at the higher levels of command [6,7]. This multi-agency interoperability can bring with it many issues when the different emergency services are required to work together, possibly having unfamiliar working practices, technology, communication styles and goals [811]. For a very large scale event there may even be a need for cross border assistance, increasing the likelihood of such issues of interoperability occurring [7,12].

For these reasons having a better understanding of the emergency services' procedures, both their own organisation (intra-team) and those of other emergency service responders (inter-team) who they will be required to work alongside, can be advantageous [2]. High level guidelines for response to CBRN incidents is provided by the North Atlantic Treaty Organisation (NATO) as a concept of operations (CONOPS) covering information gathering, assessment and dissemination, scene management, saving/protecting lives, and specialist support [13]. A previous model of CBRN response by Healey et al. [14] chronologically mapped an event for prevention, preparedness, alerting/ early response, and remediation. This model allowed for response phases and events to be established but also had no detailed information about tasks that should occur, lines of communication needing to be established and where technologies might fit into the system. Having access to technologies, such as those which can quickly detect and identify substances or track patients and evidence in this chaotic environment can aid in situational awareness, thus reducing the psychological distress placed on emergency responders [15-18].

Systems mapping methods that have previously been used to visualise a Social Technical System (STS) in other domains include AcciMaps [19] and Hierarchical Task Analysis (HTA) [20,21]. This paper describes the development of a CBRN AcciMap as a platform for development and evaluation of technology. An example of an HTA for a CBRN diagnostic technology is used to show how the 2 systems mapping tools can be used in conjunction to visualize macro and micro systems.

\section{Method}

\subsection{Accimaps}

Participants were recruited through purposive sampling requiring them to have experience of operating at Silver or Gold levels of command and having previously worked at Bronze level, giving them knowledge of all levels of the STS, and ensuring they could provide relevant CONOPS documents.

An iterative approach was used for the development of the AcciMaps with empirical data taken from both document analysis and interviews. Both open source (e.g. NATO [13]), and restricted (if access was approved) documents were read and the information from these was used for visualization of the multiple tasks and 
responsibility levels on a single map. These initial data were subsequently expanded with interviews to describe specific task activities from first blue light responder arriving on scene upwards through the command chain.

The Accimap was reviewed with a participant from each stakeholder service (fire, ambulance, police, and military) to discuss differences between written procedures (work as imagined) and operational activities (work as done). The individual service AcciMaps were compared to look for similarities and a higher abstraction level consensus AcciMap was developed. The EU final AcciMap was validated by all participants as meaningful for their country.

\subsection{Hierarchical Task Analysis (HTA)}

HTAs were created on both a macro level (mapping of the Field Trial/Exercise; FTX) and micro level (mapping of prototype technology). The macro HTAs were compiled through interviews with the lead organizer of each FTX; with information from these interviews mapped in a macro systems HTA for each FTX. These were reviewed and revised through an iterative process until the lead organisers confirmed them as an accurate depiction of the tasks in the FTX.

The micro level HTAs were created for individual technologies which were at least Technology Readiness Level (TRL) 6 and above in development indicating that it is at least sufficiently developed to be demonstrated in a relevant environment. Data were collected from document analysis (e.g. instruction manuals and user guides) and interviews with the technology developers to map out mental models of how the technology should work ('work as imagined'). The HTAs were then reviewed and validated by the developers as accurate representations.

\section{Results}

\subsection{Accimaps}

A final harmonised (consensus) Accimap was created (Figure 1) with cross-cutting themes of Communication, Planning, Action, and Reflection. Although the structure of command in an incident was similar across the EU the terminology used sometimes varied with Silver command and Bronze Command terms being described as 'Tactical', 'Incident', and 'Operational'. These levels always reported to a Gold Command (Strategic) and managed (were supported by) Specialist Blue Light Responders (S-BLR) and initial Blue Light Responders (BLR).

Working from the base of the hierarchy, the BLRs would often be first on scene as part of the conventional response to everyday emergency calls. Their role in CBRN is limited by their level of equipment and training but it was agreed across all countries that at a minimum they would recognise the scene as a possible CBRN event and pass information to the control rooms to initate dispatch of specialists (S-BLR) with greater CBRN response capabilities. 
The Bronze/On-Scene Command is responsible for ensuring all resources (equipment and personnel) are optimally used by applying the Incident Command Tactical Plan (T-Plan), and Standard Operating Procedures (SOPs). They are also 


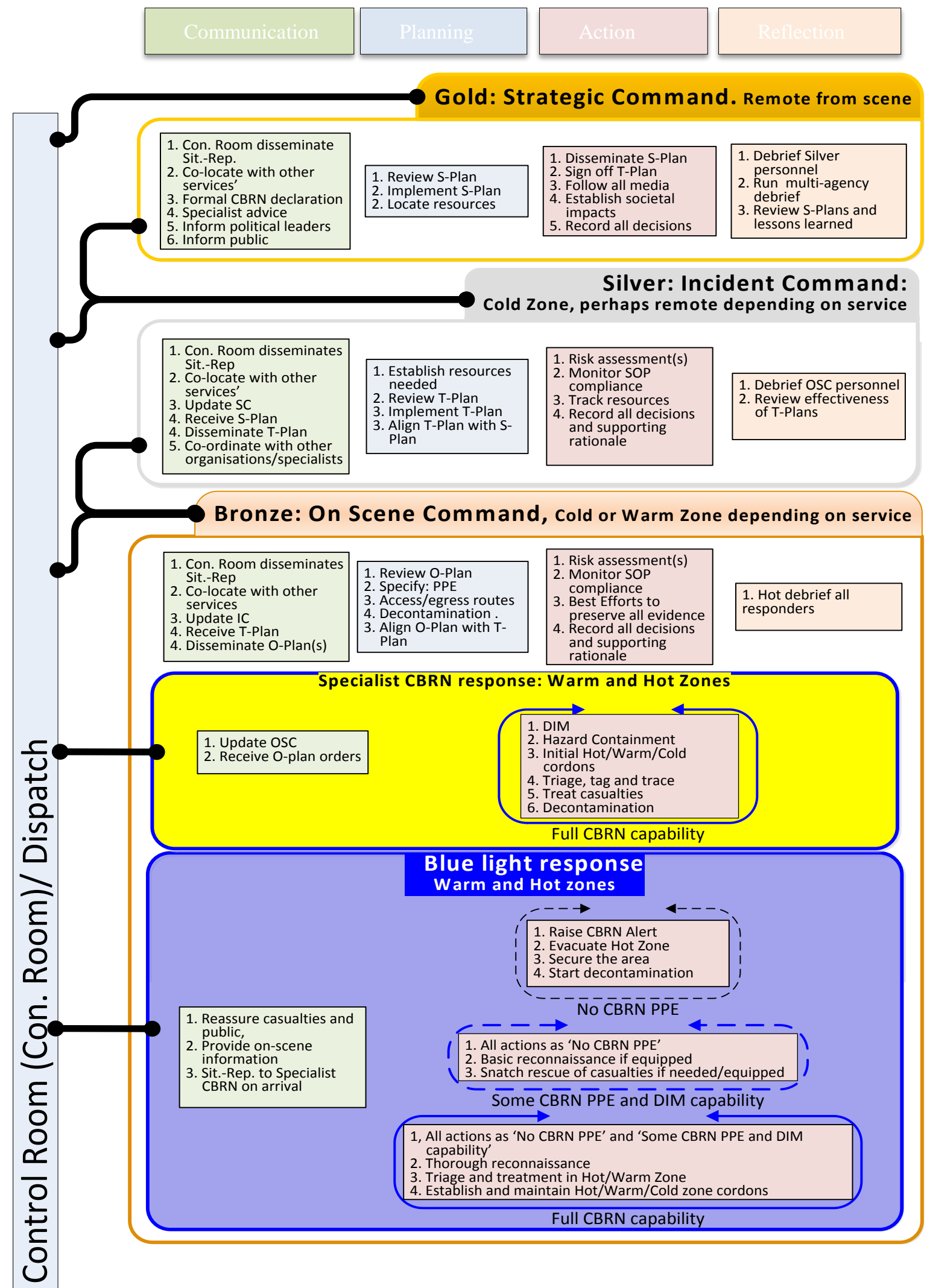

Fig. 1. EU wide Accimap (previously published in Hancox et al. [22]) 
responsible for managing the BLR and S-BLR, and apply the Operational Plan (OPlan).

Silver/Incident Command manages the T-Plan to track and monitor the resources needed in the CBRN response. They are typically, but not always (depending on service and country), located at a distance from the CBRN scene and have a broader perspective of the incident which allows them to offer advice to the Bronze/ On-scene Command. They act a point of contact for Gold and Bronze commands, controlling the information flowing up and down the STS, and reducing the likelihood of information overload.

Gold/Strategic Command implements the Strategic Plan (S-Plan) based on policies, legal frame-works and protocols. This requires managing resources on a regional, national and international level with a more 'outward facing' perspective, and acting as a point of contact for Government representatives and public messages (via the media). They also consider (plan for) limiting the after effects of the incident, so make decisions based to plan for returning to readiness ('business as usual').

Control Room/Dispatch is represented in Figure 1 as a communication spine, transmitting information up and down the hierarchy. This is most frequently achieved with the use of dedicated radio and wireless channels across all levels; communication in the STS mostly takes place only between adjacent levels. A dedicated Major Incident Control Room (Con.Room) is usually set up in later stages of the incident for each agency.

\subsection{Hierarchical Task Analysis}

HTA was used in 2 ways, firstly to expand the Accimaps and map the events (as goals, tasks, sub-tasks and plans) for two FTXs to support testing of prototype technologies in a simulated CBRN event; this was the 'macro' element to look at the system as a whole. Secondly HTAs were created for individual technologies to represent the 'micro' element of the system - how each technology would be used within the system.

Figure 2 shows an example of a technology HTA to map the series of tasks, subtasks and plans for a prototype breath analyser. The 8 subtasks give a clear and concise process from preparing the device for use through to decontamination. 
Hancox, G., Hignett, S., Kintzios, S., Pillin, H., Silmäri, J., Thomas, P. (2018) Ergonomics systems mapping for professional responder inter-operability in Chemical, Biological, Radiological and Nuclear events. . Proceedings of the $20^{\text {th }}$ Triennial Conference of the International Ergonomics Association. Florence, Italy, 26-30 August

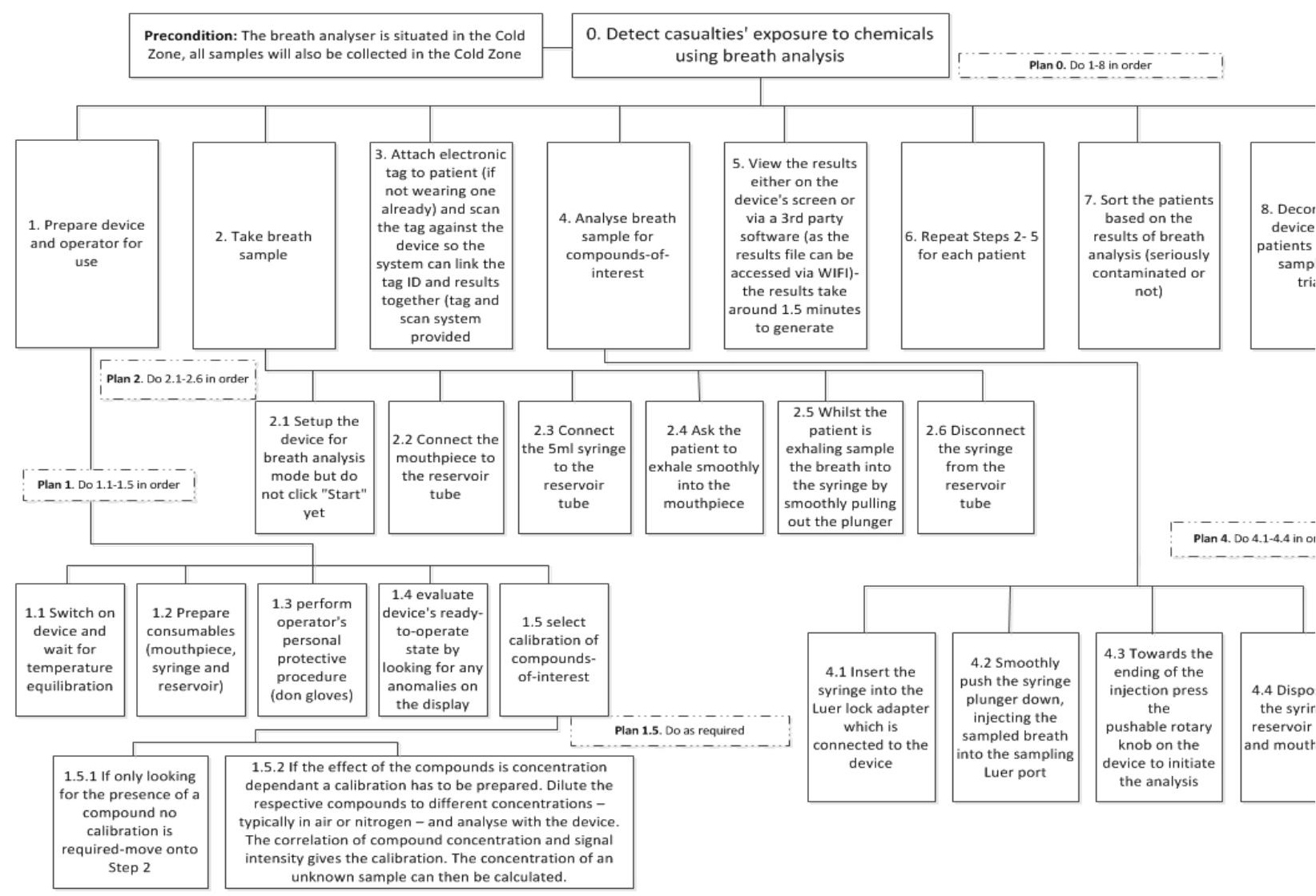

Fig. 2. Breath analysis Hierarchical Task Analysis 
Hancox, G., Hignett, S., Kintzios, S., Pillin, H., Silmäri, J., Thomas, P. (2018) Ergonomics systems mapping for professional responder inter-operability in Chemical, Biological, Radiological and Nuclear events. . Proceedings of the $20^{\text {th }}$ Triennial Conference of the International Ergonomics Association. Florence, Italy, 26-30 August

\section{Discussion}

A new consensus of an EU harmonised civilian CBRN systems (CONOPS) was achieved through cross mapping the planned responses to CBRN events in a number of EU countries (Greece, Finland, Czech Republic and UK). This shows that there are at commonalities when dealing with CBRN incidents across services and borders which support interoperability. Technology developers who may be less familiar with CBRN response procedures, may also benefit from Figure 1 with a greater understanding of the systems to support their technology integration.

The Accimap model approach taken in this paper may be sufficiently detailed for mapping EU wide CBRN responses as more specific inter-operating procedures may not be achievable as commented by Mendonça et al. [23], "extreme events occur infrequently, and no two are exactly the same. A comprehensive set of procedures to cover the space of possible events may be impossible to achieve". Nevertheless, some parts of a response, such as the task steps to use a CBRN detection technology may benefit from more detail; this was tested in this paper with using the HTA method.

The combination of the 2 methods gives both a very broad overview of the tasks occurring in a CBRN event on an EU wide scale, with details for simulated scenarios and technology use from the HTAs representing a combination of the 'macro perspective' encompassing the system as a whole, with the more 'micro perspective'. HTAs focusing on the tasks, sub-tasks and plans to use technology were useful by allowing technology developers to clearly see where their technology could fit into the macro perspective system and similarly the FTX scenario planners to see the micro tasks that need to be accommodated for successful technology use within their planned trial/exercise. The 2 approaches proved useful in complementing one another in mapping macro and micro systems so people from all audiences and backgrounds could understand what would occur in a CBRN event.

\section{Conclusions}

Inter-operability is essential in a CBRN incident response for a shared understanding of response plans and activities. For developers to design technology that efficiently works within systems of response requires an understanding of the planned responses. An adapted Accimap methodology proved useful in mapping an EU wide CBRN response in conjunction with more specific HTAs to show the numerous specific actions at both macro and micro-perspectives. 


\section{References}

1. James K. The organizational science of disaster/terrorism prevention and response: Theory-building toward the future of the field. Journal of Organizational Behavior. 32(7), 1013-1032 (2011).

2. Power N. Extreme Teams: Towards a Greater Understanding of Multi-Agency Teamwork During Major Emergencies and Disasters. American Psychologist. (2017)

http://eprints.lancs.ac.uk/88335/1/POWER_AP_PRE_PRINT.pdf, last accessed 2018/04/13.

3. Palmer I. The psychological dimension of chemical, biological, radiological and nuclear (CBRN) terrorism. Journal of the Royal Army Medical Corps. 150(1), 3-9 (2004).

4. Alexander D A., Klein S. Biochemical terrorism: too awful to contemplate, too serious to ignore: subjective literature review. The British Journal of Psychiatry. 183(6), 491-7 (2003).

5. Kako M, Hammad K, Mitani S, Arbon P. Existing approaches to chemical, biological, radiological, and nuclear (CBRN) education and training for health professionals: findings from an integrative literature review. Prehospital and disaster medicine. 33(2), 182-190 (2018).

6. Wilkinson D, Waruszynski B, Mazurik L, Szymczak AM, Redmond E, Lichacz F. Medical preparedness for chemical, biological, radiological, nuclear, and explosives (CBRNE) events: gaps and recommendations. Radiation protection dosimetry. 142(1), 8-11 (2010).

7. Centre for strategy and Evaluation Services. Ex-post evaluation of PASR activities in the field of security and interim evaluation of FP7 security research. (2011). https://ec.europa.eu/home-affairs/sites/homeaffairs/files/e-

library/documents/policies/security/pdf/interim_evaluation_of_fp7_security_ex_post_pasr _final_report_en.pdf, last accessed 2018/ 04/13.

8. Waring S, Alison L, Carter G, Barrett-Pink C, Humann M, Swan L, Zilinsky T. Information sharing in interteam responses to disaster. Journal of Occupational and Organizational Psychology. 2018. https://onlinelibrary.wiley.com/doi/full/10.1111/joop.12217, last accessed, 2018/04/13

9. Power N, Alison L. Offence or defence? Approach and avoid goals in the multi-agency emergency response to a simulated terrorism attack. Journal of occupational and organizational psychology. 90(1), 51-76 (2017).

10. House A, Power N, Alison L. A systematic review of the potential hurdles of interoperability to the emergency services in major incidents: recommendations for solutions and alternatives. Cognition, technology \& work. 16(3), 319-35 (2014).

11. Mendonça D, Jefferson T, Harrald J. Collaborative adhocracies and mix-and-match technologies in emergency management. Communications of the ACM. 50(3):44-9 (2007).

12. Home Office. CONTEST: the United Kingdom's strategy for countering terrorism. , https://www.gov.uk/government/uploads/system/uploads/attachment_data/file/97994/conte st-summary.pdf, last accessed 2018/04/13.

13. NATO. Project on Minimum Standards and Non-Binding Guidelines for First Responders Regarding Planning, Training, Procedure and Equipment for Chemical, Biological, Radiological and Nuclear (CBRN) Incidents. (2011). http://www.nato.int/nato_static_fl2014/assets/pdf/pdf_2016_08/20160802_140801-cepfirst-responders-CBRN-eng.pdf, last accessed 2018/04/13.

14. Healy MJ, Weston K, Romilly M, Arbuthnot K. A model to support CBRN defence. Defense \& Security Analysis. 25(2), 119-35 (2009). 
15. Bolic M, Borisenko A, Seguin P. Automating Evidence Collection at the Crime Scene Using RFID Technology for CBRN Events. Forensic Science Policy \& Management: An International Journal. 3(1), 3-11 (2012).

16. Stewart KA. NPS, international special forces groups, NATO collaborate to counter CBRN threats.

https://calhoun.nps.edu/bitstream/handle/10945/41344/Naval\%20Postgraduate\%20School \%20\%20NPS\%2c\%20International\%20Special\%20Forces\%20Groups\%2c\%20NATO\%20 C.pdf?sequence=1\&isAllowed=y, last accessed 2018/04/13

17. Sferopoulos R. A review of chemical warfare agent (CWA) detector technologies and commercial-off-the-shelf items. (2009), http://www.dtic.mil/dtic/tr/fulltext/u2/a502856.pdf, last accessed 2018/04/13

18. Pacsial-Ong EJ, Aguilar ZP. Chemical warfare agent detection: a review of current trends and future perspective. Front. Frontiers in Bioscience, Scholar, 5(1), 516-543 (2013).

19. Salmon PM, Cornelissen M, Trotter MJ. Systems-based accident analysis methods: a comparison of Accimap, HFACS, and STAMP. Safety science. 50(4), 158-70 (2012).

20. Annett, J., Duncan, K.D. Task analysis and training design. Occupational. Psychology. 41(1), 211-221 (1967).

21. Stanton NA. Hierarchical task analysis: Developments, applications, and extensions. Applied ergonomics. 37(1), 55-79 (2006).

22. Hancox G, Hignett S, Pillin H, Kintzios S, Silmäri J, Thomas PCL. Systems mapping for technology development in CBRN response. International Journal of Emergency Services. https://www.emeraldinsight.com/eprint/ZBSH8EQ76IFFWCDCSINB/full, last accessed 2018/04/13.

23. Mendonça D, Jefferson T, Harrald J. Collaborative adhocracies and mix-and-match technologies in emergency management. Communications of the ACM. 50(3), 44-9 (2007). 